\title{
Central bilateral macrogyria
}

INSERM

\section{Source}

INSERM. (1999). Orphanet: an online rare disease and orphan drug data base. Central bilateral macrogyria. ORPHA:2431

Central bilateral macrogyria is a neuronal migration disorder characterised by pseudobulbar palsy, developmental delay, mild mental retardation and epilepsy. It has been described in at least four children. 